http://www.jfas.info

\title{
THE STUDY OF TECHNOLOGICAL PREVENTION METHOD OF ROAD ACCIDENT RELATED TO DRIVER AND VEHICLE
}

\author{
M. N. Abdullah, M. A. M. Shukran, M. N. Ismail, K. Maskat, M. R. M. Isa and M. S. Ishak
}

Department of Computer Science, Faculty of Defense Science and Technology, National Defence University of Malaysia, Sungai BesiCsmamp, 57000 Kuala Lumpur, Malaysia

Published online: 10 September 2017

\begin{abstract}
Considering the increasing of the number cars on the roads, the rate of road accident has also increased with many people died or sustained serious injuries in a road accident. Increasing the phenomenon of road accident frequency, a study on the factors that may be associated with the occurrence of the accident was conducted. This paper also discussed about road accident prevention method based on the factors studied. The study of this paper can provide forceful data analysis support for the road traffic safety related research.
\end{abstract}

Keywords: road accident; accident prevention; road safety.

Author Correspondence, e-mail: afizi@upnm.edu.my

doi: http://dx.doi.org/10.4314/jfas.v9i3s.48

\section{INTRODUCTION}

A road accident in simplest sentences to understand refers to any accident involving at least one road vehicle, occurring on a road open to public circulation and in which at least one person is injured or killed. In other words, road accident refers to any collusion or accident occurred on a road involving any road vehicle with other vehicle or object.

Road traffic is an extremely important part to life, but the frequent road crash brings serious 
bodily harm and loss of property [1]. Each side of road car crashes contains a large amount of information and data is the most common form of the most important information records. Via mining the data of road car crash, we can analysis (sudden unplanned bad event/crash) (features/ qualities/ traits) in multi-angles, multi-level and more complete and thorough, and discover possible rules [2]. Studies have shown that road traffic injuries are a major cause of death and disability around the world, with a surprisingly big (or small) number happening in developing countries [3]. In this paper, we mainly discuss about prevention of road accident related to technologies.

Based on [4], "the critical reason of crash can be attributed to the driver, vehicle, roadway, or atmospheric condition". The first factor that related the most when road accident happened is human error. People are the moving of a road safety and the main part of road safety. In the road traffic system, the people are not only the maker of car crashes but also the victims. The people include all those who use the roads, such as drivers, passengers, walking people [5].

In [6] believes that a crash to be speeding-related if the driver was charged with a speeding-related offense or if an officer pointed to/showed that racing, driving too fast for conditions, or going beyond the posted speed limit was (something that adds something to something else) in the crash. Speeding is one of the most common factors adding/giving to traffic crashes and at a huge/extreme cost. NHTSA guesses (of a number) that the once-a-year money-based cost to (community of people/all good people in the world) of speeding-related crashes is $\$ 40.4$ billion.

In 2012, speeding was (something that adds something to something else) in $30 \%$ of all deadly crashes, and 10,219 lives were lost in speeding related crashes. Speeding-related deaths increased by $2 \%$ from 10,001 in 2011 to 10,219 in 2012 (Table 1).

Table 1.Total fatalities, speeding-related fatalities and percentage speeding-related, 2003-2012 [6]

\begin{tabular}{cccc}
\hline Year & Total Fatalities & Speeding Related Fatalities & Percent Speeding Related \\
\hline 2003 & 42,884 & 13,499 & 31 \\
2004 & 42,836 & 13,291 & 31 \\
2005 & 43,510 & 13,583 & 31 \\
\hline
\end{tabular}




\begin{tabular}{llll}
\hline 2006 & 42,708 & 13,609 & 32 \\
2007 & 41,259 & 13,140 & 32 \\
2008 & 37,423 & 11,767 & 31 \\
2009 & 33,883 & 10,664 & 31 \\
2010 & 33,999 & 10,508 & 32 \\
2011 & 32,479 & 10,001 & 31 \\
2012 & 33,561 & 10,219 & 30 \\
\hline
\end{tabular}

Another non-human factor suspected to be a cause of the increases in traffic accidents is the country's substandard public transportation service, which continues to worsen in many cases. The most common form of public transportation in most Indonesian cities is the bus, whose systems range from small to large in size. Representing a much smaller proportion are the railway and waterway modes. The low road ratio on one hand and dependency on road-based transportation modes on the other have made the traffic situation worse in the sense of poor traffic performance and safety [7].

The second factor that related the most when road accident occurred is vehicle failure. Vehicle failure is a condition when part of mechanical or motor breakdown. A breakdown in a vehicle system such as a tire, wheel or braking system inadequacy is carefully thought about/believed against driving and is likely to raise the risk of a crash. Of the guessed (number) 3,894,983 case vehicles, $6.8 \%$ had at least one bad condition as compared to $88.2 \%$ vehicles that had no bad vehicle condition. The condition of tire and wheel inadequacy had the highest percentage $(4.9 \%)$ of event [3].

\section{EXPERIMENTAL}

Regarding to [6], speeding is one of the most common factors adding to traffic crashes, "An Australian company has developed a system that lets drivers know when they are speeding. When the technology becomes commercially available, it could help lead-footed drivers avoid tickets and also save lives." It could even be used by parents to watch the changes or unusual things of teen driving. The product called SpeedAlert, links (happening or viewable immediately, without any delay) location data and speed received/got with the help of the 
Worldwide Positioning System (GPS) to a collection of the data posted speed limits stored in a driver's PDA or programmable mobile phone. The setup does not need to be hooked up to a car's speedometer. In fact, it is completely portable. A GPS receiver placed on the dashboard communicates with the PDA via a Bluetooth wireless connection. It will also work with newer phones and PDAs that have built-in GPS receivers. If a driver goes beyond the speed limit, the speed is shown on the PDA and an alert sound if the driver doesn't slow down [8]. So, the driver will alert that they had gone beyond the speed limit and will slow down.

While human factors have a powerful influence, there is another phenomenon that make it the traffic accident problem more worst is the motorbike mode. The quickly growing preference for the motorbike mode underscores a supply-demand imbalance in transportation systems in many cities, in addition to other factors like the lack of sufficient road infrastructure.

Providing sufficient and affordable public transportation is an effective means of combating motorbike use and by extension, reducing traffic accidents. Development projects for some modes of public transportation have been ongoing in Jakarta and being followed by other big cities in the country with similar aims and targets. It is further expected that various funding schemes involving the private sector not only national and sub-national budget resources will accelerate the provision of public transportation and improve overall traffic safety [7].

According to [9], "CCTV can be used to figure out road crash factors in city-based areas." It uses images that collected through the more and more (existing everywhere) use of CCTV cameras in city-based areas, as a means of increasing understanding of the causes of road car crashes. Information on causality and contributory factors is extremely important as a means of understanding why road crash happened and how the event of almost the same events may be prevented in the future. CCTV records of road crashes could provide an independent opinion about a road crash and have the possible ability to increase both the quality and amount of information available to the safety researchers.

Other than that, occurrence crashes of over-height trucks with overpasses and tunnels have been continuously reported over the years [10]. Even though the frequency of this crash might not be thought significant, the costs they involve are very high. The damages involve direct costs related to injuries or deaths for drivers or walking people and clearing/restoring the 
overpass/tunnels and happening roads, as well as indirect costs charged due to traffic delays. Over-height trucks are continuously striking low clearance overpasses and tunnels. This has led to significant damage, deaths and inconvenience to the public. Smart systems can automatically detect and warn oversize trucks and have been introduced to provide the trucks with the opportunity to avoid a crash [10]. "It (figures out the worth, amount or quality of) the (ability to actually be done) of using computer vision to detect over-height trucks. In the proposed method, video streams are collected from a video camera (for recording people) attached on the overpass/tunnel and processed to measure truck heights.

The height is measured using line detection and blob watching and following which locate upper and lower points of a truck in pixel coordinates. The pixel coordinates are then translated into 3D world coordinates. Proof-of-idea experiment results show/indicate the high performance of the proposed method and its (possible greatness or power) in (accomplishing or gaining with effort) (producing a lot for a given amount of money) supervising of over-height trucks in the transportation system."

Besides that, according to [3], the condition of tire and wheel inadequacy had the highest percentage which is $4.9 \%$ of event. Because of this, a tire-pressure monitoring system (TPMS) is an electronic system designed to watch for changes of the air pressure inside the air-related tires on different types of vehicles. It used to be that driver had to manually check your tire pressure every week. The TPMS does that for driver. It sounds like such a simple thing, but it actually quite a new and interesting technology. Small sensors reside inside of your tire's valve stem and measure the air pressure inside the tire. When the reading drops below a preset value, a warning light inside the vehicle lights up in order to alert the driver [11].

In [4] state that the first factor that related the most when road accident occurred is human error [4]. Systems such as Driver Attention Monitor found in some Lexus vehicles already keep an eye on drivers by using a small infrared camera mounted on the steering column that detects their head position. If it senses that a driver is looking away from the road for a certain length of time, a warning sounds to draw attention forward. It also tested early model systems from Continental and Volvo that can track drivers' head as well as eye movements to decide/figure out if they are looking away from the road. The Cornell-Stanford project also 
uses cameras inside the car to detect drivers' head movements and the direction of their look. Camera images are fed to a computer that uses face-detection and watching and following software to identify movements connected with lane changes and turns. The software then matches this data with information from driver help sensors to layer in what is happening outside the vehicle. A warning or even automatic braking and steering can happen if it senses that an accident is a threat [12].

\section{RESULTS AND DISCUSSION}

Based on the data or statistic from road accidents database of a certain place and city, and then analysis the road accident data, finally obtained each road accident causes mode. There are several conditions that can be related when an accident happened. Human error can be described as a major factor that can cause an accident. From the data collected, there are four major factors that related to human error which is driving habit, sleepiness, age and obesity, and excessive daytime sleepiness (EDS). Hence, several methods have been discussed to overcome human error that can cause the road accident. First method to overcome this is by providing sufficient and affordable public transportation is an effective means of combating motorbike use and by extension, reducing traffic accidents. Development projects for some modes of public transportation have been ongoing in Jakarta and being followed by other big cities in the country with similar aims and targets. It is further expected that various funding schemes involving the private sector not only national and sub-national budget resources will accelerate the provision of public transportation and improve overall traffic safety [7].

Other than that, SpeedAlert can be used to prevent driver from get over speed which is it links without any delay location data and speed received/got with the help of the GPS to a database of posted speed limits stored in a driver's PDA or programmable mobile phone. "A GPS receiver placed on the dashboard communicates with the PDA via a Bluetooth wireless connection. It will also work with newer phones and PDAs that have built-in GPS receivers.

If a driver goes beyond the speed limit, the speed is shown on the PDA and an alert sound if the driver does not slow down [8]." So, the driver will alert that they had exceeded the speed limit and will slow down. 
Besides that, CCTV can be used to decide/figure out road crash factors in city-based areas. Information on causality and contributory factors is extremely important as a means of understanding why crash happened and how the event of almost the same events may be prevented in the future. CCTV records of crash could provide an independent opinion about a crash and have the possible ability to increase both the quality and amount of information available to the safety (person who works to find information). Other than that, systems such as Driver Attention Monitor found in some Lexus vehicles already keep an eye on drivers by using a small infrared camera mounted on the steering column that detects their head position. If it senses that a driver is looking away from the road for a certain length of time, a warning sounds to draw attention forward.

The second factor that related the most when road accident occurred is vehicle failure. Vehicle failure is a condition when part of mechanical or motor breakdown. A breakdown in a vehicle system, such as a tire, wheel, or braking system inadequacy is carefully thought about/believed against driving and is likely to raise the risk of a crash. To prevent wheel system deficiency, tire-pressure monitoring system (TPMS) can be used to monitor the air pressure. TPMS is an electronic system designed to watch the changes of the air pressure inside the (air-related/air-operated) tires on different types of vehicles. It used to be that driver had to manually check your tire pressure every week. TPMS does that for the driver. It sounds like such a simple thing, but it actually quite a new and interesting technology. Small sensors reside inside of your tire's valve stem and measure the air pressure inside the tire. When the reading drops below a preset value, a warning light inside the vehicle lights up, warning driver.

Besides that, over-height trucks are continuously striking low clearance overpasses and tunnels. This has led to significant damage, deaths and inconvenience to the public. Smart systems can automatically detect and warn oversize trucks and have been introduced to provide the trucks with the opportunity to avoid a crash [10].

It (figures out the worth, amount, or quality of) the (ability to actually be done) of using computer vision to detect over-height trucks.In the proposed method, video streams are collected from a video camera (for recording people) attached on the overpass/tunnel and 
processed to measure truck heights. The height is measured using line detection and blob watching and following which locate upper and lower points of a truck in pixel coordinates. The pixel coordinates are then translated into 3D world coordinates. Proof-of-idea experiment results show/indicate the high performance of the proposed method and its (possible greatness or power) in (accomplishing or gaining with effort) (producing a lot for a given amount of money) watching/supervising of over-height trucks in the transportation system.

\section{CONCLUSION}

In conclusion, this paper shows that the critical reason of an accident can be attributed to the human error and vehicle failure. This paper also shows that how the road accident can be preventing by use the CCTV. It can be used to decide/figure out road (sudden unplanned bad event/crash) factors in city-based areas and also by using the systems such as Driver Attention Monitor, which is found in some Lexus vehicles that already keep an eye on drivers by using a small infrared camera mounted on the steering column that detects their head position. Besides that, SpeedAlert can be used to prevent driver from get over speed which is it also can prevent (sudden unplanned bad event/crash) happened that caused by speed. Other than that, tire-pressure monitoring system (TPMS) can be used to watch (for changes, unusual things, etc.) the air pressure in order to prevent wheel system (not having enough of something). Also, Smart systems can automatically detect and warn oversize trucks and have been introduced to provide the trucks with the opportunity to avoid a crash. It (figures out the worth, amount or quality of) the (ability to actually be done) of using computer vision to detect over-height trucks. The study of this paper can provide forceful data analysis support for the road traffic safety related research.

\section{ACKNOWLEDGEMENTS}

This research was done in conjunction with the main research which is Research on Automated Vehicle's Crash Notification Using Android Application. 


\section{REFERENCES}

[1] He M. The system research on the traffic accident data analysis based on data mining. Hunan: Changsha University of Science and Technology, 2009

[2] Cheng T. Research on road traffic accident data mining and application. Shenzhen: Harbin Institute of Technology, 2009

[3] Seth DO. Brake failure and its effect on road traffic accident in Kumasi Metropolis, Ghana. International Journal of Science and Technology, 2012, 1(9):1-10

[4] U.S Department of Transportation (2008) National Highway Traffic Safety Administration

[5] Tian R, Yang Z, Zhang M.Method of road traffic accidents causes analysis based on data mining. In IEEE International Conference onComputational Intelligence and Software Engineering, 2010, pp. 1-4

[6] U.S Department of Transportation. National Highway Traffic Safety Administration, 2014

[7] Soehodho S. Public transportation development and traffic accident prevention in Indonesia. IATSS Research, 2017, 40(2):76-80

[8] Robert R B. New in-car device warns speeding drivers. New York: Live Science, 2016

[9] Florence C, Tight M.Use of CCTV to determine road accident factors in urban areas. Accident Analysis and Prevention, 2006, 38(6):1197-1207

[10] Dai F, Park MW, Sandidge M, Brilakis I.A vision-based method for on-road truck height measurement in proactive prevention of collision with overpasses and tunnels. Automation in Construction,2015, 50:29-39

[11] Keith M. Road accident prevention: Should we rely on technology to save lives? Florida: Global Dispatch Inc., 2015

[12] Doug N. New technology may prevent accidents by reading drivers' body language.New Jersey: Forbes, 2015

\section{How to cite this article:}

Abdullah M N, Shukran M A M, Ismail M N, Maskat K, Isa M R M, Ishak M S. The study of technological prevention method of road accident related to driver and vehicle. J. Fundam. Appl. Sci., 2017, 9(3S), 621-629 